\title{
FORMULATION AND CHARACTERIZATION OF LAFUTIDINE NANOSUSPENSION FOR ORAL DRUG DELIVERY SYSTEM
}

\author{
NOOR MOHAMMED DAWOOD*, SHAIMAA NAZAR ABDAL-HAMMID, AHMED ABBAS HUSSIEN
}

Department of Pharmaceutics, College of Pharmacy, University of Baghdad, Iraq-Baghdad

Email: noorhassanyassir2018@gmail.com

Received: 13 Oct 2017, Revised and Accepted: 09 Jan 2018

\section{ABSTRACT}

Objective: The objective of this study was to prepare nanosuspension of a practical water insoluble antiulcer drug which is lafutidine to enhance the solubility, dissolution rate with studying the effect of different formulation variables to obtain the best formula with appropriate physical properties and higher dissolution rate.

Methods: Nanosuspension of lafutidine was prepared using solvent anti-solvent precipitation method using Polyvinylpyrrolidone K-90(PVP K-90) as the stabilizer. Ten formulations were prepared to show the effect of different variables in which two formulations showed the effect of stabilizer type, three formulations showed the effect of stabilizer concentration, two formulations showed the effect of combination of polymer with surfactant such as tween 80 , three formulations show the effect of stirring speed and three formulations prepare to show the effect of addition of cosurfactant such as tween 20 . All these formulations are evaluated for their particle size and entrapment efficiency and in vitro release. The selected one was evaluated for zeta potential, scanning electron microscope, atomic force microscopy, Fourier transforms infrared spectroscopy, differential scanning calorimetry, saturation solubility and stability study.

Results: The formulations (F3-F10) were in the nano size. The optimum concentration of the stabilizer was in the formulation when the drug: polymer: surfactant ratio 1:4:4 and the optimum stirring speed was $1500 \mathrm{rpm}$. Dramatic effect on the particle size reduction was found by the addition of co-surfactant (tween 20) in formulation F7 that has a particle size $15.89 \pm 1.8 \mathrm{~nm}$. The selected formula F7 showed an enhanced dissolution profile (10 $\mathrm{min}$ ) compared to the pure drug at all-time intervals.

Conclusion: The results show that the formulation that contains drug: PVP-K90: tween 80: tween 20 in ratio 1:4:2:2 is the best one and can be utilized to formulate lafutidine nanosuspension.

Keywords: Lafutidine, Solubility, Dissolution rate, Bioavailability

(c) 2018 The Authors. Published by Innovare Academic Sciences Pvt Ltd. This is an open-access article under the CC BY license (http://creativecommons.org/licenses/by/4.0/) DOI: http://dx.doi.org/10.22159/ijap.2018v10i2.23075

\section{INTRODUCTION}

Approximately $75 \%$ of new chemical entities are poorly soluble in aqueous medium and many even in the organic medium [1]. Solubility is quantitatively defined as the concentration of solute in a saturated solution at a certain temperature, while qualitatively may be defined as the spontaneous interaction of two or more substances for formation of a homogeneous molecular dispersion [2]. So many problems arising from poor new drug solubility in drug research and development. Also, low solubility limits the drug dissolution rate, resulting in low bioavailability of the oral drug [3]. As a result, extensive attempts have been carried out to solve the problems of low aqueous solubility and increase the dissolution rate of hydrophobic drugs. Some of the conventional approaches are particle size reduction method which subclasses into a) micronization: There are general methods of particle size reduction, such as milling and spray drying, rely upon mechanical stress to disaggregate the active compound. In addition to that micronization approach successfully enhanced the bioavailability of poorly watersoluble drugs such as griseofulvin and felodipine [4, 5]. b) nanonization: is the production of drug nanocrystals, and it is a common approach to overcome poor drug solubility in water. Nanonization produces drug particles below 1 micron either by the bottom-up methods such as precipitation and self-assembly or topdown technologies such as milling and high-pressure homogenization. Nanonization has an advantage of increased saturation solubility of the drug together with the increase in dissolution rate [6].

Nanosuspensions technology has been conceived as a candidate for efficient delivery of hydrophobic drugs and applied to poorly soluble drugs since this technology results in the formulation that is having high dissolution velocity and increased saturation solubility [7]. Other advantages of nanosuspension are that it can be easy fabrication into a tablet or a capsule or dried nanosuspension form which can easily be re-dispersible [8].
Nanosuspension is a submicron colloidal dispersion of drug particles. So a pharmaceutical nanosuspension is defined as a very finely colloid, biphasic, dispersed, solid drug particles in the aqueous vehicle, with size below $1 \mu \mathrm{m}$, without any matrix material, stabilized by surfactants and polymers (stabilizer) [9].

Lafutidine is a yellowish white crystalline powder[10], with a melting point of $\left(98.87-101.57^{\circ} \mathrm{C}\right)$, It is freely soluble in glacial acetic acid, DMF, soluble in methanol, sparingly soluble in dehydrated ethanol, very slightly soluble in ether, practically insoluble in water with $\log p=3.8$ [11]. Lafutidine has pka $=3.9$ and according to Biopharmaceutical Classification System (BCS), It belongs to class II of drug category [12].

Lafutidine is a new H2-receptor antagonist, after absorption in the small intestine; it reaches gastric cells by the systemic circulation, then directly and quickly binds to gastric cell histamine $\mathrm{H} 2$ receptors, resulting in prompt inhibition of gastric acid secretion. It is selectively absorbed from the upper part of small intestine (absorption window) [13]. The drug is predominantly metabolized in the liver mainly by microsomal enzyme CYP3A4, and CYP2D6 and its major metabolites are sulfonyl lafutidine and hydroxylated lafutidine [14]. Fasting plasma concentration of the unchanged drug observed as Tmax: $0.8 \pm 0.1 \mathrm{~h}$; Cmax: $174 \pm 20 \mathrm{ng} / \mathrm{ml}$. It has a biological half-life of $3.0 \mathrm{~h}$ [15].

The aim of the study was to the formulation of lafutidine as nanosuspension to improve its solubility and enhance in vitro dissolution rate.

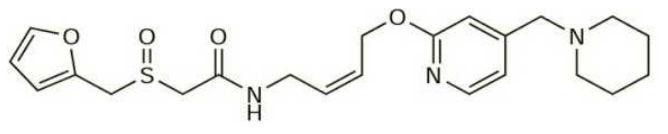

Fig. 1: Chemical structure of lafutidine [12] 


\section{MATERIALS AND METHODS}

\section{Materials}

Lafutidine powder was purchased from Hangzhou hyper chemicals limited, Zhejiang, China. Tween 80 and tween 20, was purchased from Scharlau S. L Spain. (PVP K-90) was provided by Hangzhou hyper chemicals limited, Zhejiang, China. Dialysis membrane70 provided by HIMEDIA (Mumbai, India). All other chemicals and solvents were of analytical reagent grade, and deionized water also was used in this study.

\section{Methods}

Preparation of lafutidine nanosuspension by precipitation method

Nanosuspension precipitation method is used to prepare oral nanosuspension of lafutidine using a different concentration of polymer and surfactant. In brief, $10 \mathrm{mg}$ of lafutidine was dissolved in an organic solvent ( $1 \mathrm{ml}$ methanol). Deionized water containing the stabilizer (PVP K-90or tween 80) alone at the drug: stabilizer ratio 1:8 or in the combination of PVP K-90 with tween 80 at the different concentration or in combination with co-surfactant (tween 20), which acts as the antisolvent system. This was followed by the addition of the organic solution into the antisolvent solution by the help of a syringe pump, under mechanical agitation of different speeds using homo disperser for $60 \mathrm{~min}$ at $25 \pm 1^{\circ} \mathrm{C}$ to allow organic solvent to evaporate and get the desired nanosuspension [16]. The batches were prepared according to the formulation design (table 1).

\section{Evaluation of the prepared nanosuspension \\ Particle size and size distribution}

Particle size determination was done by using Angstrom Advanced Inc. ABT-9000 USA particle size analyzer which is a dynamic light scattering works by measuring the intensity of light scattered by the molecules in the sample as a function of time, at scattering angle $90^{\circ}$ and a constant temperature of $25^{\circ} \mathrm{C}$. From the analysis, the average particle size which is also called volume moment mean, (mean diameter in $\mathrm{nm}$ ) reflects the size of those particles which constitute the bulk of the sample volume and it was measured for all the prepared formulas. The polydispersity index (PDI) which is a measure of the width of the size distribution of each formula of LAF nanosuspension also determined, it is a measure of the distribution of particle size of nanoparticles obtained from a particle analyzer, PDI is an index of spread or variation or width within the particle size distribution. Also, the analyzer determines the specific surface area of each sample [17].

Table 1: Composition of lafutidine nanosuspension formulation

\begin{tabular}{|c|c|c|c|c|c|c|c|c|c|c|}
\hline Substance & F1 & F2 & F3 & F4 & F5 & F6 & F7 & F8 & F9 & F10 \\
\hline LAF (mg) & 10 & 10 & 10 & 10 & 10 & 10 & 10 & 10 & 10 & 10 \\
\hline PVP-K90 (mg) & 80 & - & 50 & 40 & 30 & 50 & 40 & 30 & 50 & 50 \\
\hline Tween 80 (mg) & - & 74.8 & 28 & 37.4 & 46.7 & 14 & 18.7 & 23.4 & 28 & 28 \\
\hline Tween 20 (ml) & - & - & - & - & - & 13.6 & 18.2 & 22.7 & - & - \\
\hline Methanol (ml) & 1 & 1 & 1 & 1 & 1 & 1 & 1 & 1 & 1 & 1 \\
\hline Water $(\mathrm{ml})$ & 30 & 30 & 30 & 30 & 30 & 30 & 30 & 30 & 30 & 30 \\
\hline Stirring speed (rpm) & 1500 & 1500 & 1500 & 1500 & 1500 & 1500 & 1500 & 1500 & 500 & 3000 \\
\hline
\end{tabular}

F: formula, LAF: Lafutidine, PVP K-90: Polyvinylpyrrolidine k-90, rpm: round per min

\section{Determination of entrapment efficiency (EE) of nanosuspension}

$10 \mathrm{ml}$ of nanosuspension was centrifuged at $6000 \mathrm{rpm}$ for $20 \mathrm{~min}$. The supernatant solution was filtered and separated. $1 \mathrm{ml}$ of this filtrate was diluted with water and the absorbance at maximum $\lambda$ max was measured by UV spectrophotometer using water as blank [18]. The amount of free drug in the formulations was measured and the entrapment efficiency is then calculated from Eq.1

$$
\text { E. } \mathrm{E} \%=\frac{(\text { Total drug in formula-free drug) } * 100}{\text { Total drug in formula }}
$$

The results were analyzed in triplicate and standard deviations are reported.

\section{In vitro dissolution profile of nanosuspension}

In vitro drug release for nanosuspension was done by using Himedia dialysis membrane (MWCO $12 \mathrm{KD}$ ). Volume containing $10 \mathrm{mg}$ of lafutidine of (F3-F10) nanosuspension was placed in the pretreated dialysis bag and drug release was done using USP dissolution apparatus II containing $900 \mathrm{ml}$ of dissolution medium at $37 \pm 0.5{ }^{\circ} \mathrm{C}$. The speed of the paddle was $100 \mathrm{rpm}$. The formulation of lafutidine nanosuspension was subjected to the drug release studies in media of $0.1 \mathrm{~N} \mathrm{HCl} \mathrm{(pH} \mathrm{1.2)} \mathrm{in} \mathrm{comparison} \mathrm{with} \mathrm{a} \mathrm{pure} \mathrm{drug.} \mathrm{Samples} \mathrm{(5} \mathrm{ml)}$ were withdrawn at intervals of $5,10,15,20,30,40,50,60,70,80$, 100, 110 and $120 \mathrm{~min}$ respectively), and replenished with the equivalent volume of fresh dissolution medium to maintain the constant volume. Then, samples were filtered and assayed spectrophotometrically on UV spectrophotometer at $286 \mathrm{~nm}$ wavelength. The experiment repeated in triplicate for each formulation [19].

\section{Zeta potential}

Zeta potential of the selected formulation of lafutidine nanosuspension was measured by using (NanoSeries, Nano-ZS, Malvern Instruments, UK). A zeta potential value of $\pm 30 \mathrm{mV}$ is required as a minimum for physically stable nanosuspension stabilized by electrostatic repulsion only. While zeta potential of about $\pm 20 \mathrm{mV}$ is sufficient to of high-intensity the nanosuspension system stabilized by a combination of steric and electrostatic stabilization [20].

\section{The freeze-drying of selected formula}

Freeze drying or lyophilization was carried out using christ (ALPHA 1-4 LD plus) to retrieve nanoparticles in a dried-powder state from the nanosuspensions, to complete characterization of nanosuspension and show the effect of freeze drying on nanoparticles size and solubility so water-removal was conducted through freeze-drying. The selected formula was used containing $2 \% \mathrm{w} / \mathrm{w}$ mannitol as the cryoprotectant, to prevent agglomeration was frozen in a refrigerator at $-70{ }^{\circ} \mathrm{C}$ for $24 \mathrm{~h}$. Then the sample was lyophilized using vacuum freeze dryer at a controlled temperature of $(-44){ }^{\circ} \mathrm{C}$ and the pump operating at the pressure of $2.5 \times 10$ pascals over the range of 48-72 hr. The obtained powder was used for further studies [21].

\section{Fourier transforms infrared spectroscopy (FTIR)}

The fourier transforms infrared spectroscopy spectra of pure lafutidine and lyophilized powder of the selected formula were obtained using FTIR spectrophotometer (FTIR-8300 Shimadzu, Japan) by potassium bromide (KBr) pellet method. This study was achieved to identify any sign of interaction between the drug and stabilizer used. The spectrum obtained was in between the wave number of 4000-400 cm-1[22].

\section{Scanning electron microscopy (SEM)}

Scanning electron microscope used for observing the morphology of samples, SEM of pure lafutidine, and lyophilized powder was confirmed by direct deposition of powder on double-sided carbon tape and coated with gold; the analysis of the particle size was 
performed using the UTHSCSA Image Tool software. Five to six high resolution and high magnification pictures of SEM representative of the sample were used to find the particle size. The program was used to measure the average size of the particles seen in each of the SEM picture [23]

\section{$X$-ray powder diffraction}

Powder x-ray diffraction can be used to confirm the crystalline nature of materials. So, this information is used to verify whether the substances are crystalline or amorphous. The diffractograms of lafutidine and lyophilized powders of the selected formulation were obtained for analysis. The study was confirmed by using Shimadzu XRD-6000 powder X-ray diffractometer at continuous scan range of 10-80 degree. The operating voltage was $40(\mathrm{kV})$ and current $30 \mathrm{~mA}$ [24].

\section{Statistical analysis}

The experimental results are given as mean triplicate samples standard deviation (SD) and were analyzed according to one-way analysis of variance (ANOVA) using Sigma Plot 11 software at which the results would be significant if $p<0.05$, and the results would be nonsignificant if $\mathrm{p}>0.05$.

\section{RESULTS AND DISCUSSION}

\section{Particle size analysis and polydispersity index measurement}

The effect of different parameters on the particle size and polydispersity index was studied using ten different formulations. The mean particle size (effective diameter) for formulations varied in the wide range from $6.358 \pm 0.0 \mathrm{~nm}$ to $1188 \pm 1.7 \mathrm{~nm}$. The particle size and PDI for different formulations of different parameters is showing in table 2 .

Table 2: The particle size, and PDI of different formulations

\begin{tabular}{lll}
\hline Formula no. & P. S. \pm SD* & PDI \pm SD* \\
\hline F1 & $1188 \pm 1.7$ & $0.324 \pm 0.0$ \\
F2 & $805.2 \pm 1.7$ & $0.489 \pm 0.0$ \\
F3 & $22.9 \pm 0.0$ & $0.048 \pm 0.0$ \\
F4 & $73.0 \pm 11.9$ & $0.893 \pm 0.0$ \\
F5 & $63.55 \pm 0.0$ & $0.278 \pm 0.0$ \\
F6 & $19.08 \pm 0.0$ & $0.405 \pm 0.0$ \\
F7 & $15.89 \pm 1.8$ & $1.0 \pm 0.0$ \\
F8 & $6.358 \pm 0.0$ & $0.196 \pm 0.0$ \\
F9 & $36.14 \pm 0.0$ & $0.481 \pm 0.0$ \\
F10 & $59.5 \pm 0.0$ & $0.703 \pm 0.0$ \\
\hline
\end{tabular}

*SD standard deviation, n=3, P. S.: Particle size, PDI: Polydispersity index

\section{Effect of stabilizer type on the particle size and polydispersity index}

Two formulations were used to show this effect F1, F2. The best stabilizer was in F2 (tween 80 ) which has particle size 805.2 \pm 1.7 $\mathrm{nm}$. Also, this formulation show PDI in the value of 0.489 and this low value will indicate good stability of the nanosuspension. The effect of stabilizer type shown in the fig. 2 . The choice of suitable stabilizers are the most important factors to control the size and stability of the nanosuspension during nanoprecipitation methods [25]. Although; the mechanism of action of PVP K-90 which was used as hydrophilic polymers to stabilize nanosuspensions physically by steric stabilization; but they gave larger particle in ratios 1:8 drug: stabilizer in $\mathrm{F} 1(\mathrm{p}<0.05)$ than particle size of $\mathrm{F} 2$ which contain tween 80 , this may be attributed to the insufficient affinity of stabilizers to drug molecule. However, if there is no affinity between the particle surface and the polymer, the attractive forces between two particles become dominant due to depletion of polymer from the gap of two particles (depletion force) [26].

\section{Effect of combination of surfactant with polymer on particle} size and polydispersity index

F3 was used to show the effect of combination of tween 80 (used as surfactant) with PVP K-90 (used as polymer) as compared with F1 and F2 that used these stabilizers alone (fig. 3), When PVP K-90 used as a primary stabilizer in F1, could not significantly decrease the particle size $(p>0.05)$ to nanosized particles; therefore, it could not be used as the single stabilizer for the nanosuspension. The use of tween 80 combined with another stabilizer (PVP K-90) as in fig. 3 may disperse drug particle into the aqueous solution and decrease the particle size [27]. The combination of surfactant (tween80) with PVP K-90 provide the electrostatic-steric mechanism, surfactant found to influence the particle size which helps in preventing growth and stabilize the particles primarily by adsorption at the solid-liquid interface and reduction of the interfacial tension leading to an increased rate of nucleation [28].

The most significant effect $(\mathrm{p}<0.05)$ of surfactant combination with one polymer was shown in formulas that contain tween 80 or PVPK90 as primary stabilizer, as in F1and F2 respectively at ratio 1:8 (drug: primary stabilizer), the particle size was $1188 \mathrm{~nm}$ and 805.2 nm respectively, while in F3 in which tween 80 combined with PVP K-90 at drug: polymer: surfactant ratio 1:5:3 the particle sizes were $22.9 \mathrm{~nm}$. That means the combination has the good surface affinity and could form a substantial mechanical and thermodynamic barrier at the interface of drug molecule [29]. Polydispersity index values of F3 was 0.048 , indicate that these formulas are monodisperse standard, there are significant differences $(\mathrm{p}<0.05)$ from PDI values of F1 and F2 that were 0.324-0.489 indicate that these formulas are midispersed standard.

Effect of stabilizer concentration on the particle size and polydispersity index

Three formulations were used to show this effect F3, F4, and F5. In fig. 4 the particle size of F5 containing PVP K-90 and tween 80 at drug: polymer: surfactant ratio 1:5:3 was increased significantly $(\mathrm{p}<0.05)$ from $22.9 \mathrm{~nm}$ to $73 \mathrm{~nm}$ in $\mathrm{F} 4$ when the surfactant concentration raised to drug: polymer: surfactant ratio $1: 4: 4$ and then the particle size decrease significantly $(\mathrm{p}<0.05)$ to $5.248 \mathrm{~nm}$ in F5.

It was observed that with an increase in surfactant concentration in the nanosuspension from the particle size of the nanosuspension decreases. This was due to the decrease in relative viscosity, which led to decrease in particle size. It means that hydrodynamic diameter of particle decreased with increase in the concentration of the surfactant. The concentration of surfactant affected on particle size because too little concentration of stabilizer induces agglomeration or aggregation and too much concentration promotes Ostwald ripening [30].

Effect of addition co-surfactant on particle size and polydispersity index

The addition of co-surfactant is also preferred for long-term stabilization and decrease particle size significantly $(\mathrm{p}<0.05)$ as in fig. 5, F6-F8 studied the effect of the combination of surfactants (tween 80 and tween 20) on the particle size that range 6.358-19.08 $\mathrm{nm}$ which smaller than F3, F4 and F5 that contain one surfactant (tween 80), these findings are in accordance with another study whose particle sizes was lower and better stability when stabilized the formulation with surfactant mixtures compared with 
formulations with only one surfactant [31]. PDI of F8 and F6 were 0.196 , and 0.405 respectively this show that these formulas were dispersed while F7 was polydisperse because it had PDI equal to 1.0.

\section{Effect of stirring speed on the particle size and polydispersity} index of prepared nanosuspension

Three different speeds 500, 1500 and $3000 \mathrm{rpm}$ were used to prepare three formulations F9, F3, and F10 to show this effect as in fig. 6. In this study the optimums speed at the drug: polymer: surfactant ratio 1:5:3 was found to be $1500 \mathrm{rpm}$ that produce mean particle size $22.9 \pm 0.0 \mathrm{~nm}$. PDI of these formulations was in the range of $0.048-0.703$. The result suggested that lafutidine nanoparticles were nonsignificantly affected ( $>0.05)$ by stirring speed, the decreased particle size with increased stirring speed is due to an intensification of micromixing (i. e, mixing of molecular level) between multi-phases. High micromixing efficiency increased mass transfer and the rate of diffusion between the multi-phases which induced high homogeneous supersaturation in short time, thus rapid nucleation to produced smaller drug particle. In addition to that, a high stirring speed prevents the particle growth by preventing their aggregation. Hence the formation of smaller and more uniform drug particles with high stirring speed [32]

However, further increase in the stirring speed led to increasing in the particle size $(p>0.05)$ of nanosuspension during precipitation method that resulted in non-uniform formulations with visible settling due to the aggregation of particles, this could be due to mechanical agitation and non-uniform mixing producing local regions of supersaturation during anti-solvent precipitation [33].

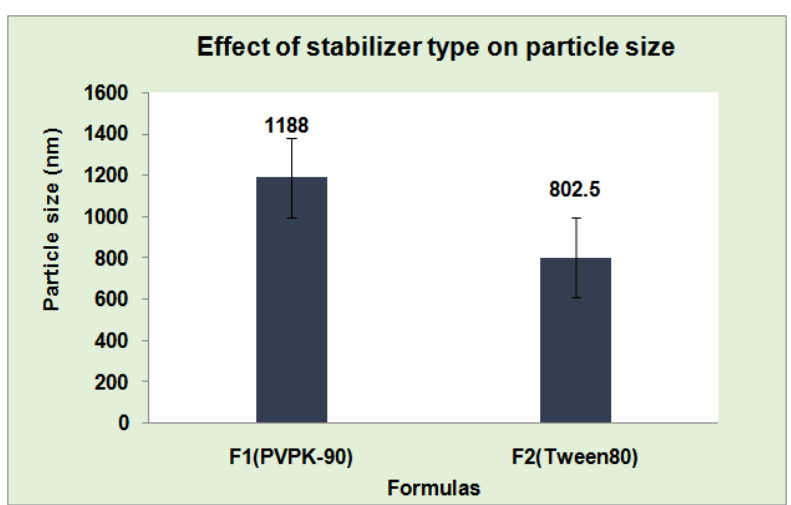

Fig. 2: Effect of stabilizer type on the particle size of nanosuspension (Results as an as mean, $n=3$ )

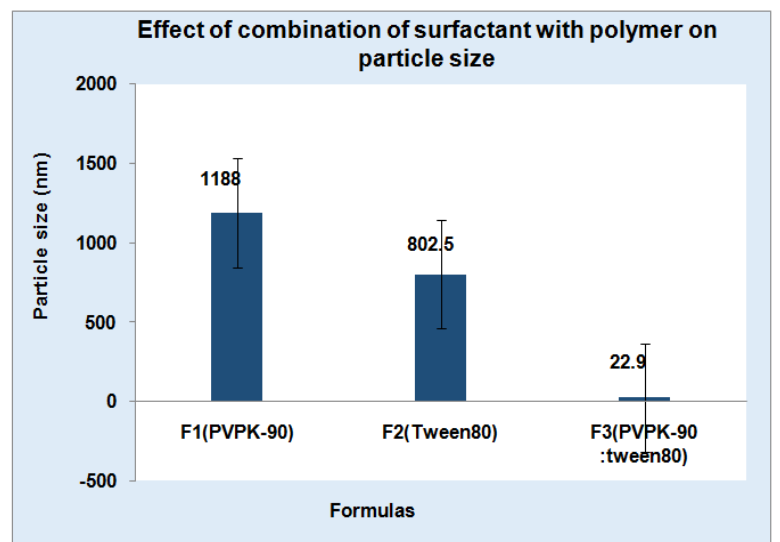

Fig. 3: Effect of a combination of the surfactant with polymer on the particle size of nanosuspension $(n=3)$

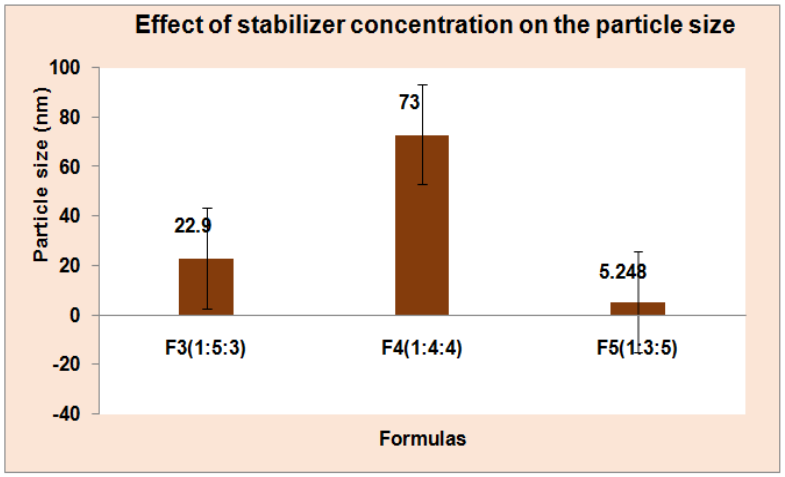

Fig. 4: Effect of stabilizer concentration on the particle size of nanosuspension (Results are expressed as mean, $n=3$ )

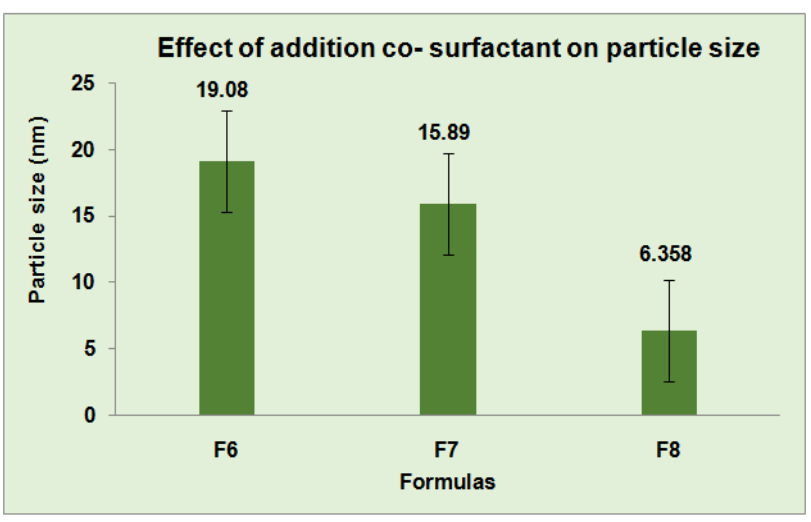

Fig. 5: Effect of addition of co-surfactant on particle size $(n=3)$

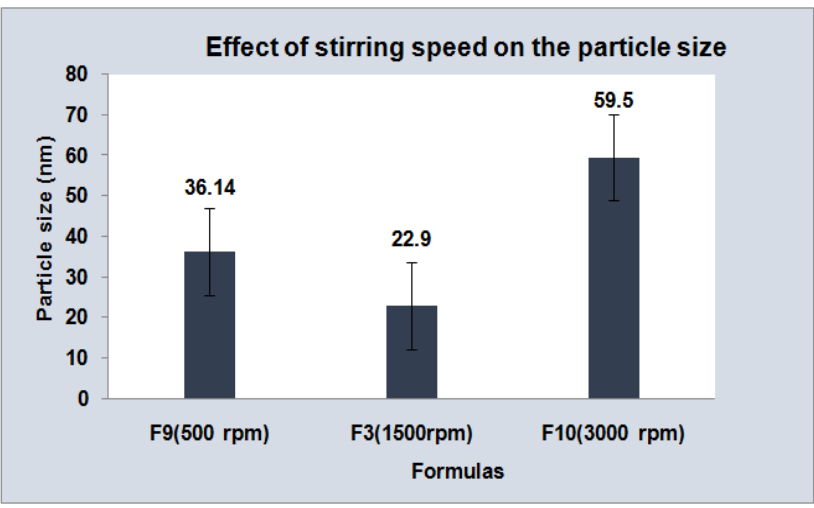

Fig. 6: Effect of addition of stirring speed on particle size (Results are expressed as mean, $n=3$ )

\section{Drug entrapment efficiency}

The Percentage drug entrapment efficiency of the formulations was calculated and the results were $95.604 \%, 98.54 \%, 96.34 \%, 98.43 \%$, 98.74\%, 98.54, 94.56\% and 97.5 for F3, F4, F5, F6 F7, F8, F9 and F10 respectively. The drug entrapment efficiency of F7 was high when compared to other formulations. Drug entrapment efficiency was significantly affected by the addition of non-ionic surfactants (combination of tween80 with tween 20) with ratio of drug: polymer: surfactant (1:4:4) with higher EE\% (98.74\%) in F7 (fig. 8) which could be due to decreased partitioning of LAF into the outer aqueous phase and better dispersion obtained by adding a hydrophilic surfactants [34]. 


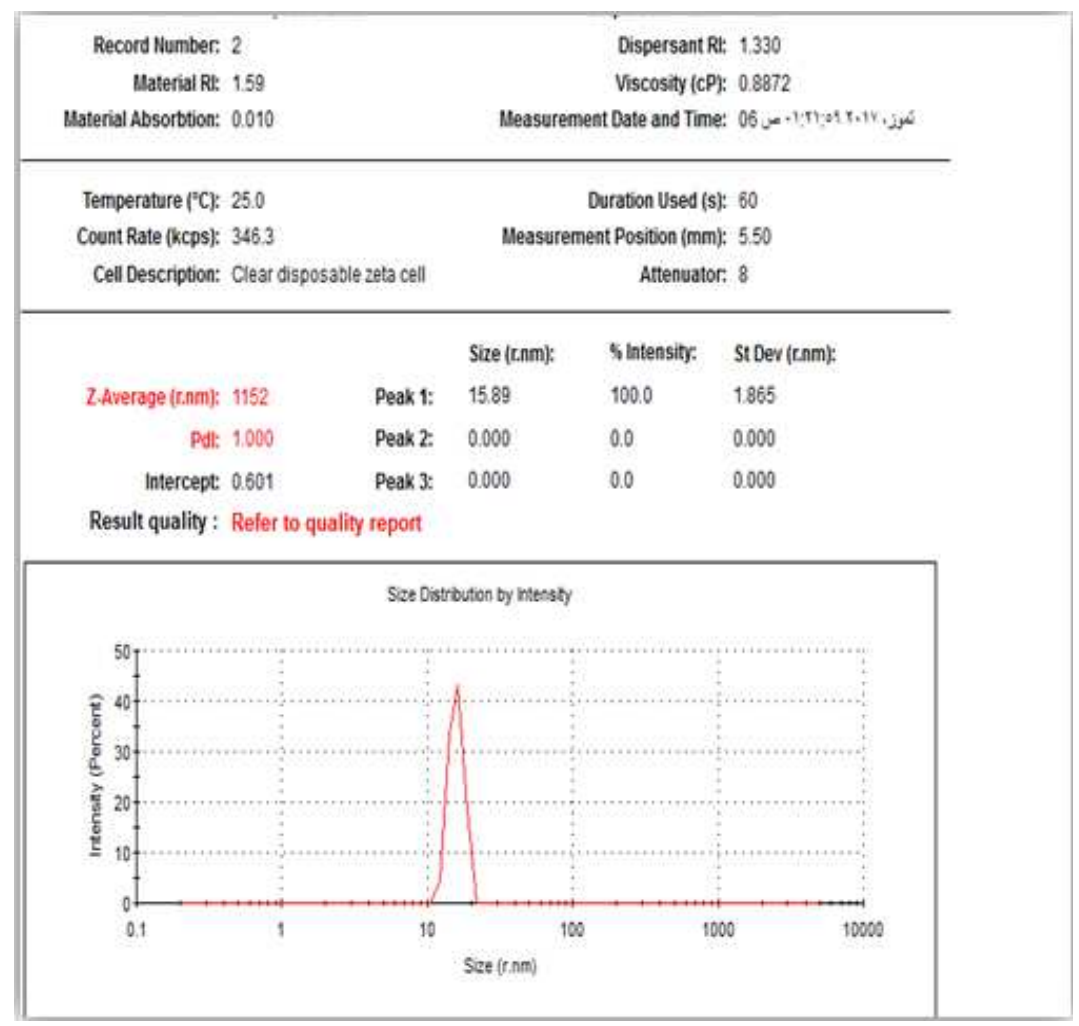

Fig. 7: Particle size distribution of the selected formula (F7)

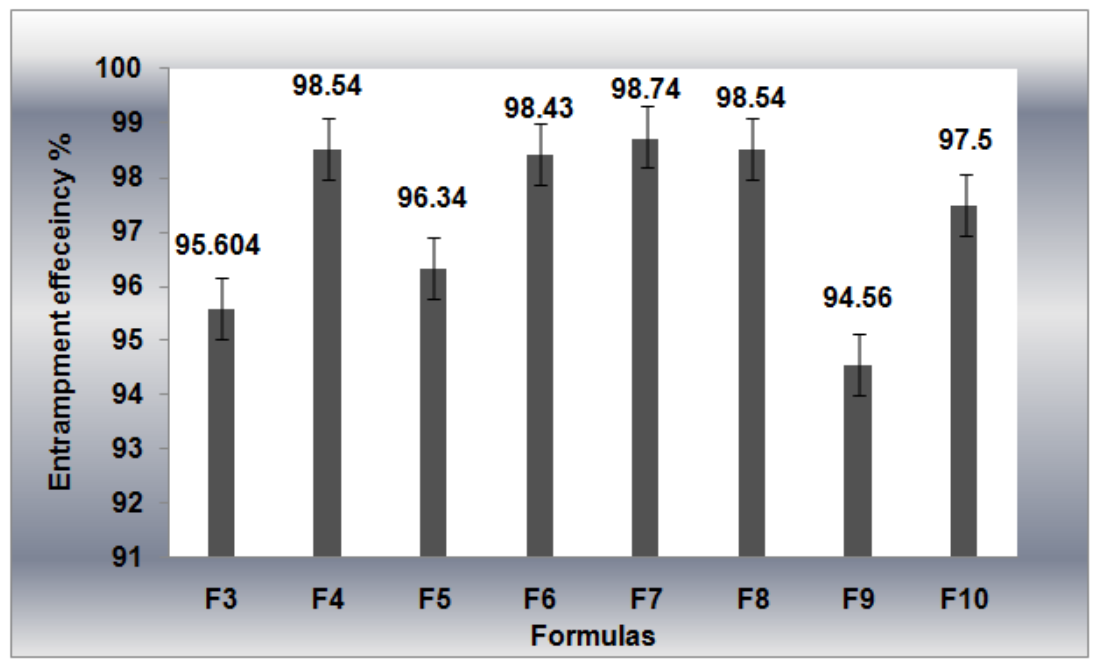

Fig. 8: Drug entrapment efficiency of the prepared formulation of lafutidine nanosuspension (Results are expressed as mean, $n=3$ )

\section{In vitro dissolution study}

The dissolution profile of the formulas that in nanosize (F3-F10) were studied in $0.1 \mathrm{~N} \mathrm{HCl}$ of $\mathrm{pH} 1.2$ to determine the best formula that gives the best release in first 10 min. The release of F3-F10 is presented $0.1 \mathrm{~N} \mathrm{HCl}$ of pH 1.2 in fig. (9). From the study, the results showed that the formula F7 that contain PVP K-90, tween 80 and tween 20 stabilizers gave the best release in $10 \mathrm{~min}$ in comparison with other formulas and the formula shows a maximum cumulative percentage drug release of $100 \%$ within $10 \mathrm{~min}$.

From the above result depending on the particle size and PDI will be the formula no. F7 which has the mean particle size $(15.89 \pm 0.0 \mathrm{~nm})$ and E. E\% (98.74). F7 was considered as the selected formula because it had the highest dissolution rate, highest entrapment efficiency percentage and low particle size when compared with another formula. This formula is selected for zeta potential measurement study, lyophilization, and further study.

\section{Zeta potential}

The zeta potential for the selected formulation of lafutidine nanosuspension was- $23 \mathrm{mV}$ as shown in fig. 11 . The charge was negative due to adsorbed tween 80 , tween 20 and PVP K-90 on the drug particles; however, this result of zeta potential proposes that the nanosuspension was adequately stabilized. It reflects the electrical potential of particles and is influenced by the composition of the particles and the medium in which it is dispersed. Zeta potential gives certain information about the surface charge properties and furthers the long-term physical stability of the nanosuspension. The obtained value for selected formulation indicates stable nanosuspension [35]. 


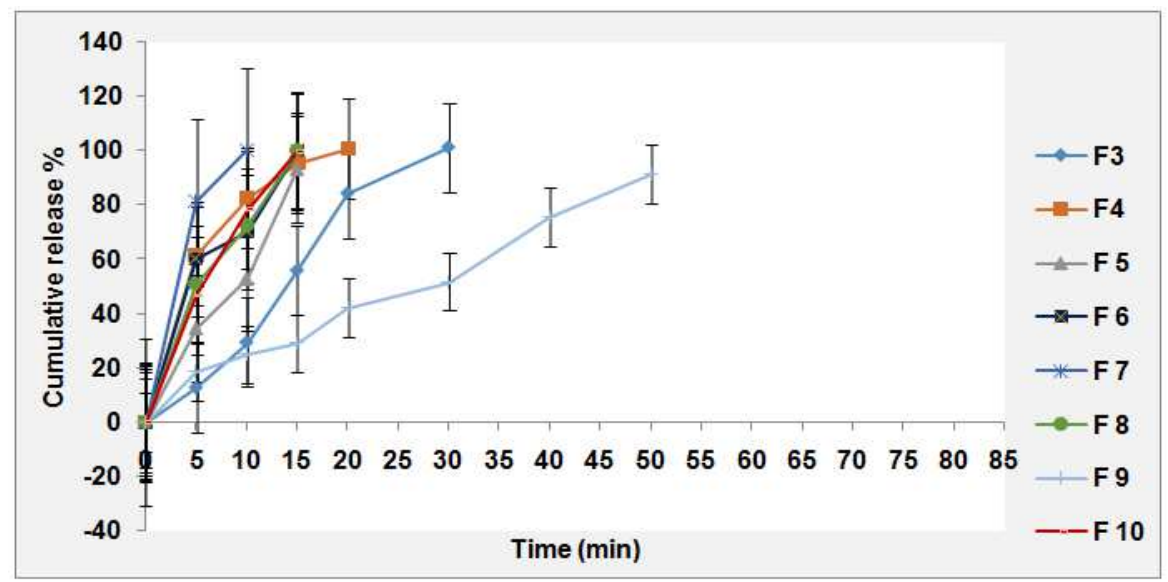

Fig. 9: In vitro drug release profile of lafutidine formulation nanosuspension in $0.1 \mathrm{~N} \mathrm{HCl}$ at $37 \pm 0.5^{\circ} \mathrm{C}(\mathrm{n}=3$ )

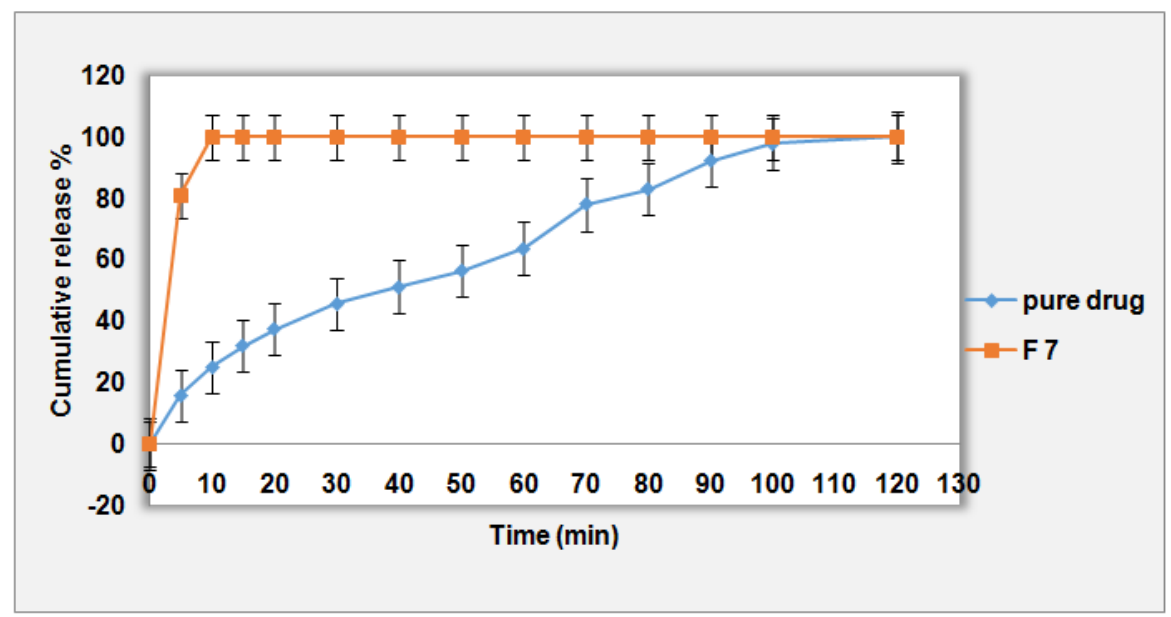

Fig. 10: In vitro drug release profile of selected formula (F7) compared with pure powder lafutidine in $0.1 \mathrm{~N}$ expressed as mean, $n=3$ )

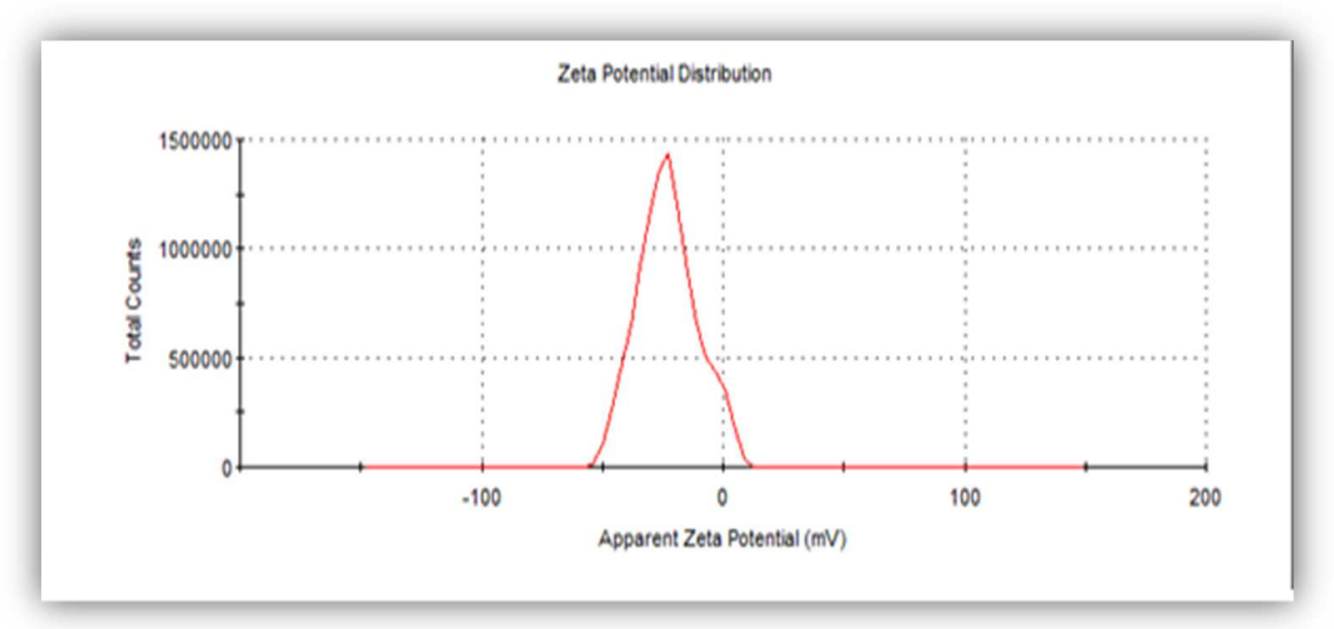

Fig. 11: Zeta potential of the selected formula (F7)

\section{Saturation solubility of freeze-drying nanosuspension}

The batch F7 (lafutidine: PVP K-90: tween 80: tween 20 1:4:2:2) was selected for freeze drying. In this study, $2 \%$ of mannitol was added as the cryoprotectant for avoiding nanocrystals aggregation/ agglomeration. Mannitol containing samples showed good redispersibility upon manual shaking. The results of the solubility study indicated that pure lafutidine had a very low solubility in water $(0.078 \mathrm{mg} / \mathrm{ml})$ which considered as practically insoluble in water, while the saturation solubility of lafutidine nanoparticle in lyophilized powder was $(125.5 \mathrm{mg} / \mathrm{ml})$ greater than that of pure drug which considered as freely soluble in water. This may be due to the reduction in particle size of lafutidine to nano size which results in exposure of more surface area and enhanced hydrophilicity; these 
were responsible for the significantly enhanced $(\mathrm{p}<0.05)$ saturation solubility [36].

\section{Fourier transforms infrared spectroscopy}

The Fourier transforms infrared spectra of pure lafutidine shown in fig. 12 (A) and that of the lyophilized powder of the selected formula
(F7) intensity in fig. 12 (B). FTIR spectra of lafutidine nanosuspension show no change in shifting the position of the lafutidine nanosuspension functional groupspeak and this will indicate there was no an interaction between the drug and the stabilizer PVP K-90 and other excipients (tween80 and tween 20) used in the formulation [37].
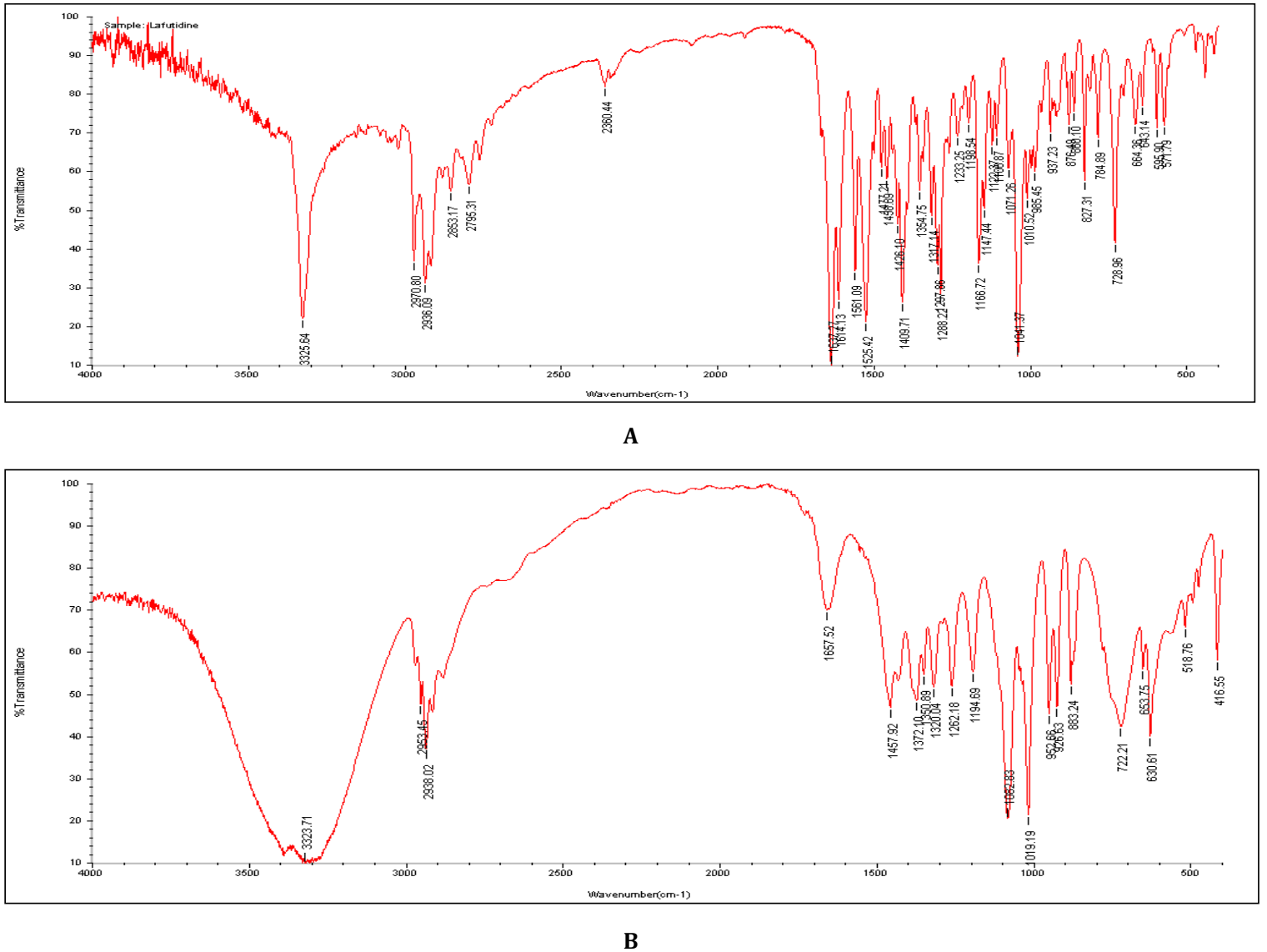

Fig. 12: Fourier transforms infrared spectroscopy of A) lafutidine and B) lyophilized powder

\section{Scanning electron microscope}

Scanning electron microscope of pure lafutidine, PVP K-90 and lyophilized powder are presented in fig. $(13,14$, and 15$)$ at $1 \mathrm{~K}, 5 \mathrm{~K}$, $10 \mathrm{~K}, 50 \mathrm{~K}$ and 500x (this only for PVP K-90) magnification. The scanning electron microscope study for pure lafutidine powder showed large particles with crystalline needle shape with the smooth surface, while scanning electron microscope of PVP K-90

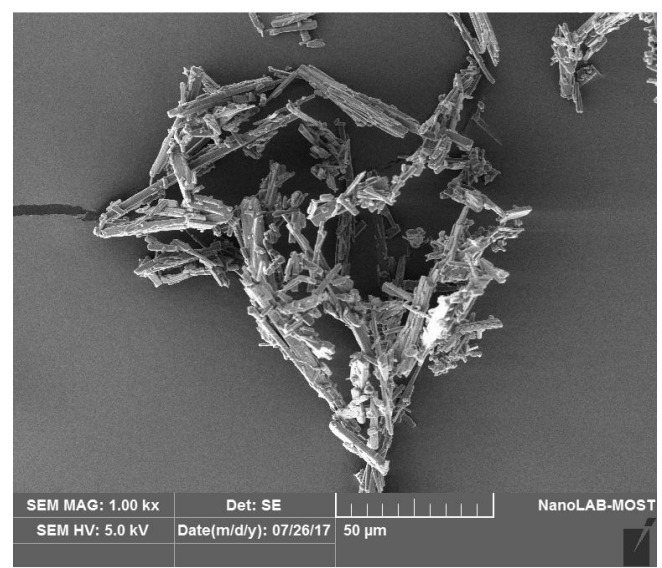

A elucidated the irregular shape with the rough surface of PVP K-90 particle because it was the amorphous polymer [38].

Scanning electron microscope of lyophilized powder at $1 \mathrm{~K}, 5 \mathrm{~K}, 10 \mathrm{~K}$ and $50 \mathrm{~K}$ of magnification revealed that the decreased the particle size with some of the crystalline needle structure of drug this problem may mean that by the addition more stabilizer and more cryoprotectant.

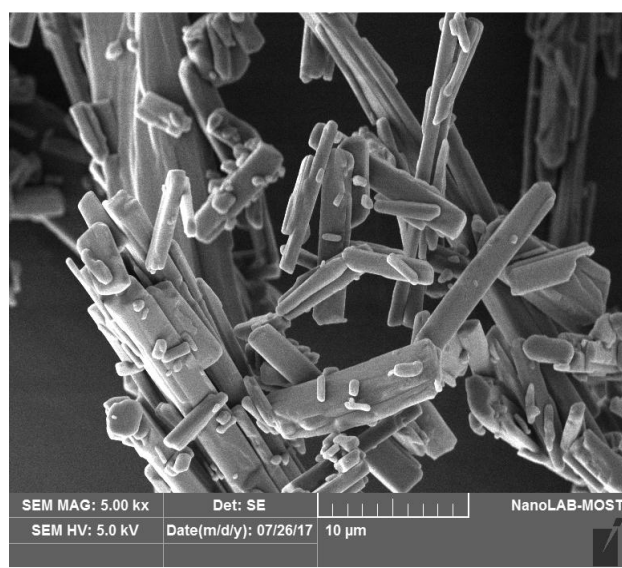

B 


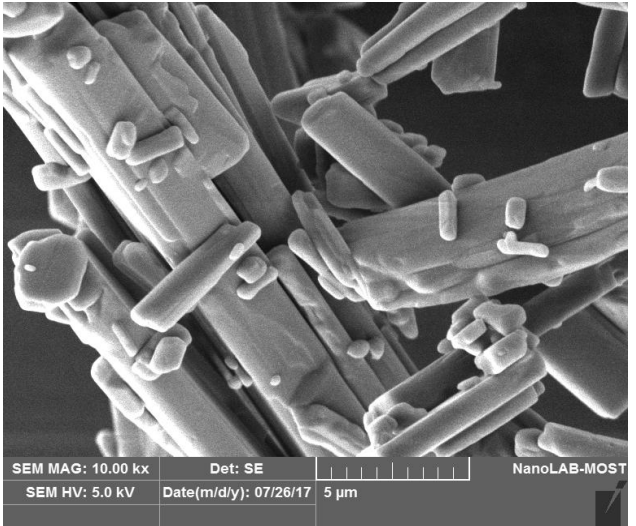

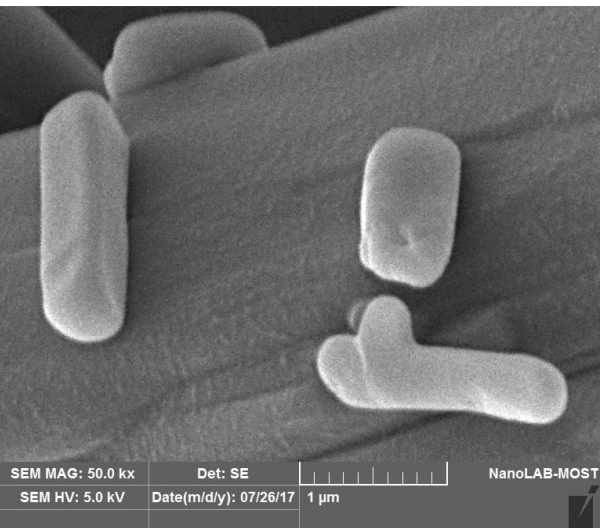

D

Fig. 13: Scanning electron microscope of pure lafutidine (A, B, C, and D) at $1 \mathrm{~K}, 5 \mathrm{~K}, 10 \mathrm{~K}$ and $50 \mathrm{~K}$ magnification respectively

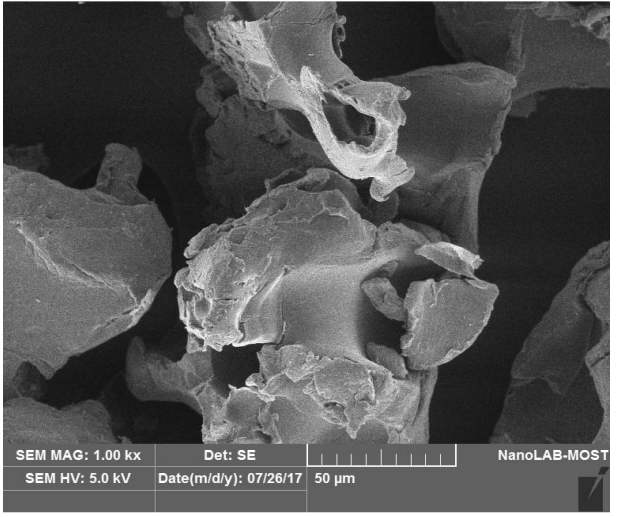

A

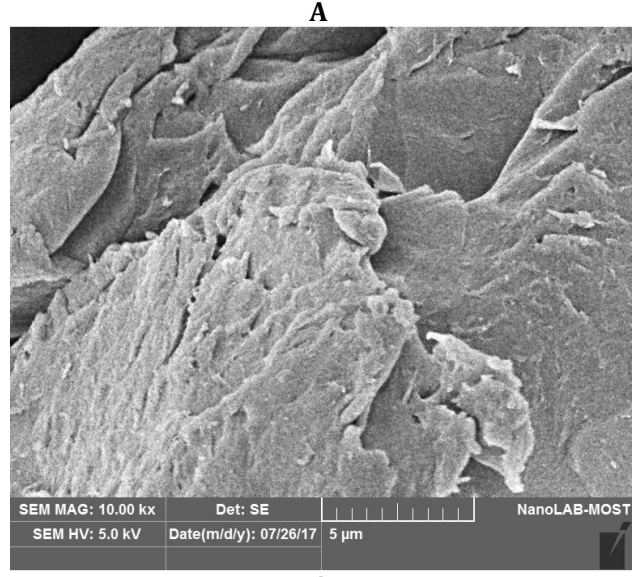

C

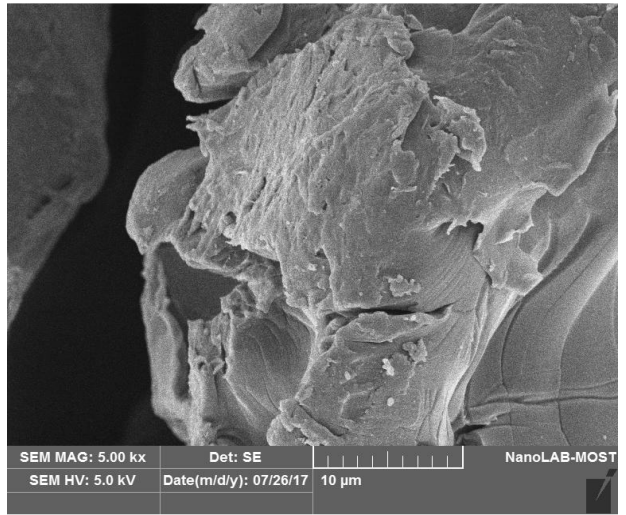

B

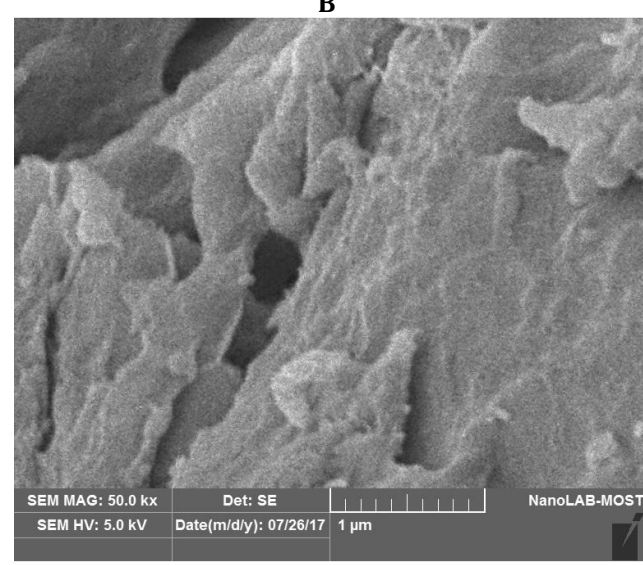

D

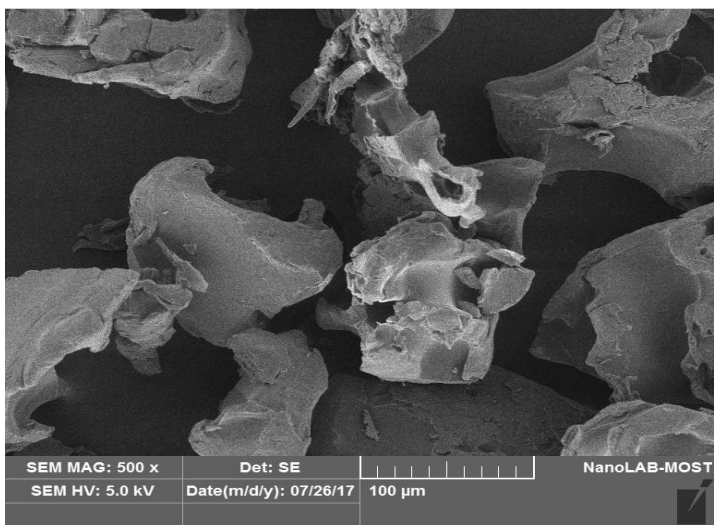

E

Fig. 14: Scanning electron microscope of PVP K-90 (A, B, C, D, and E) at $1 \mathrm{~K}, 5 \mathrm{~K}, 10 \mathrm{~K}, 50 \mathrm{~K}$ and $500 \mathrm{X}$ magnification respectively 

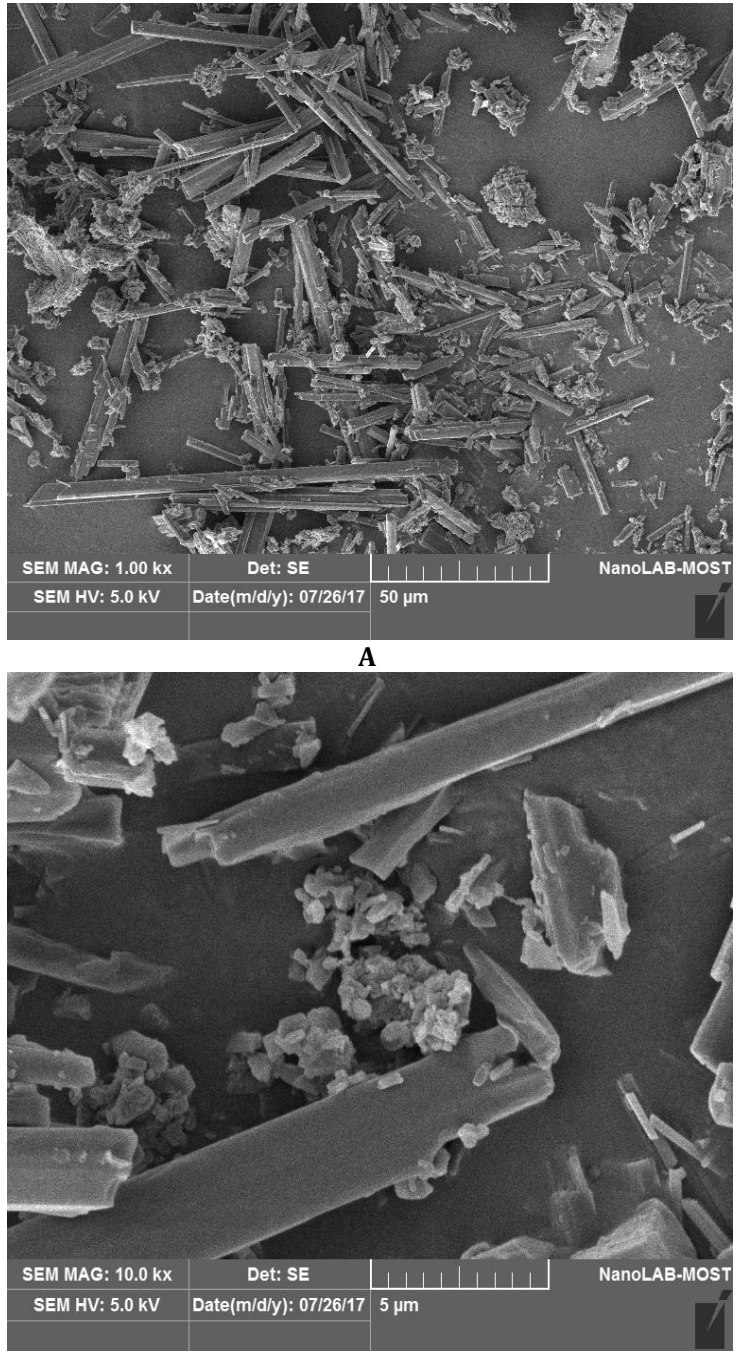

C
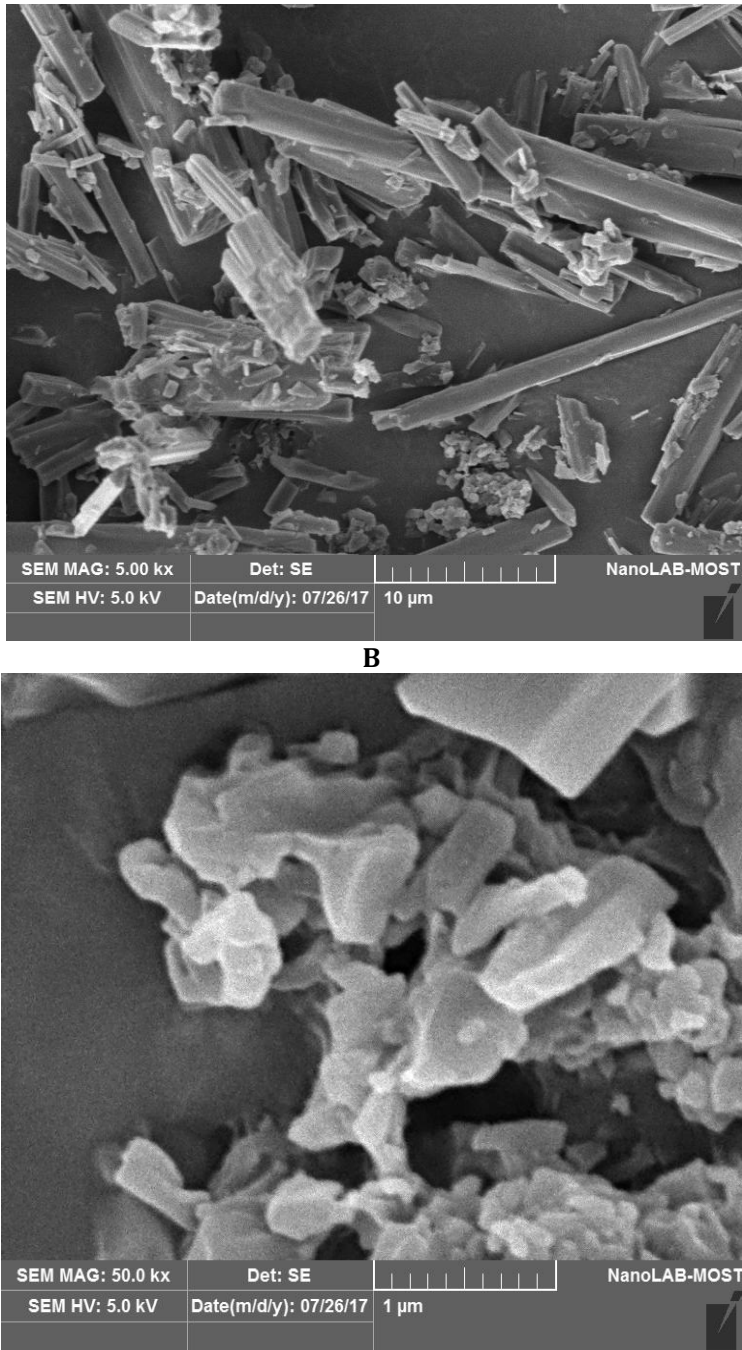

D

Fig. 15: Scanning electron microscope of lyophilized powder (A, B, C, and D) at $1 \mathrm{~K}, 5 \mathrm{~K}, 10 \mathrm{~K}$ and $50 \mathrm{~K}$ magnification respectively

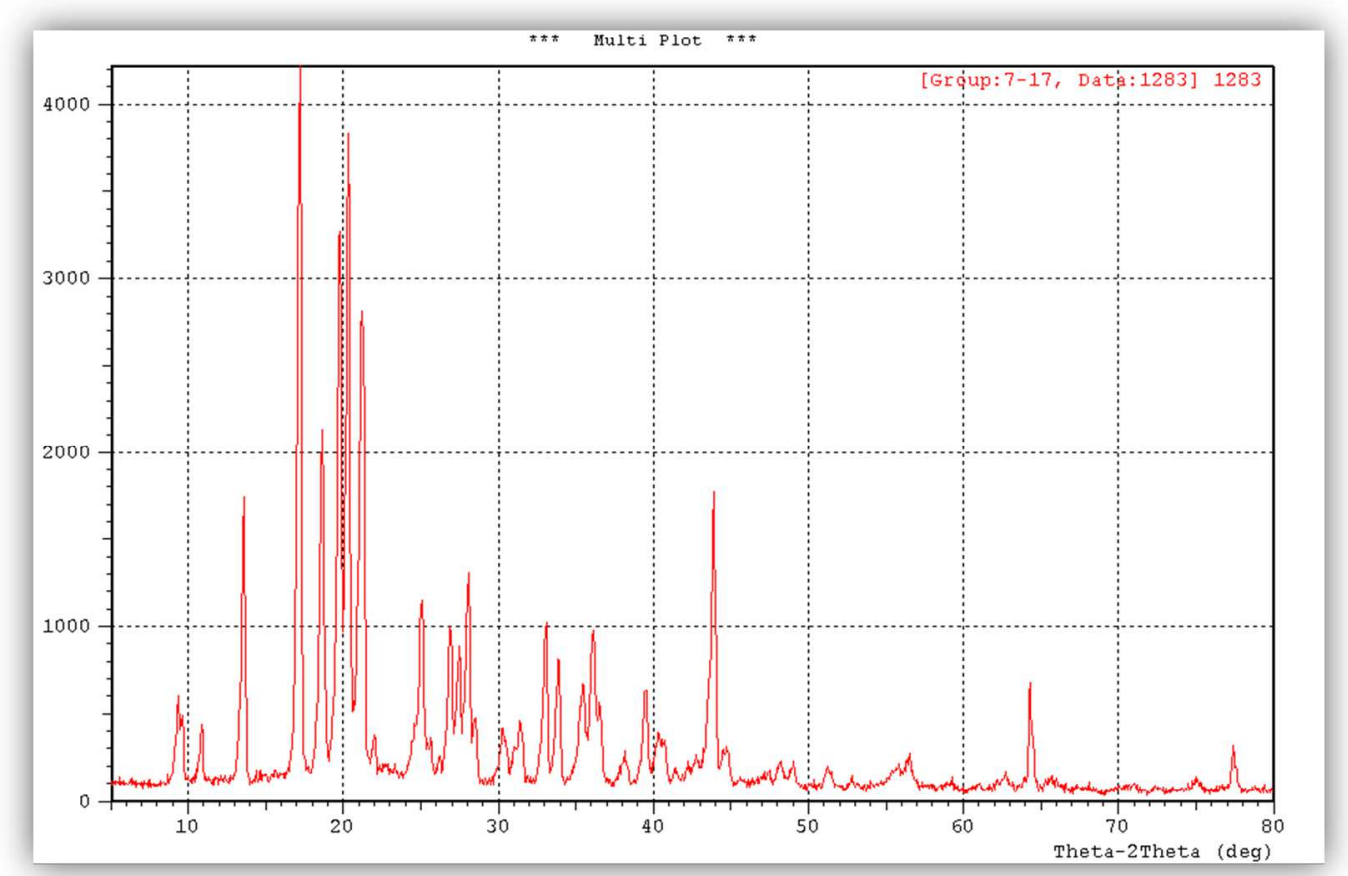

Fig. 16: Powder X-ray diffraction analysis of pure lafutidine 


\section{Powder X-ray diffraction analysis (PXRD)}

To confirm the physical state of lafutidine, PVP K-90 and lyophilized powder x-ray diffraction were performed. The Powder X-ray diffraction analysis patterns of lafutidine as a pure drug exhibited intense crystalline peaks at the $2 \theta$ angle as in fig. 16 , the strongest three peaks were $17.2^{\circ}, 19.8^{\circ}$, and $20.3^{\circ}$. The diffraction patterns of PVP K-90 demonstrated in fig. 17. PVPK-90 indicated the halo pattern was revealing amorphous nature of polymer as in it's diffractogram and characterized by low intense peak. However, the strongest peaks of PVP K-90 at the $2 \theta$ angle were $11.29^{\circ}, 43.9^{2}$ and $64.29^{\circ}$. The diffused peaks at higher angles confirm the semi-crystalline nature of the polymer [39]. However, the characteristic crystalline peak at the $2 \theta$ angle of $20.3^{\circ}$ became lower intensity peak, and strongest peaks of $17.2^{\circ}, 19.8^{\circ}$ disappeared in the pattern of lyophilized powder as in fig. 18 producing another peak at the $2 \theta$ angle of $5.69^{\circ}$ and $20.6^{\circ}$. This study suggested that there was no significant difference in characteristic peaks position of lafutidine in the lyophilized powder. Accordingly, all types of energy input during preparation and the attendance of stabilizer did not change the crystallinity of lyophilized nanosuspension powder. A just difference detected between the coarse powder, and lafutidine nanosuspension was in the peak intensity and presented of high-intensity peaks, probably attributed to particle size reduction, stabilizer at the surface [40].

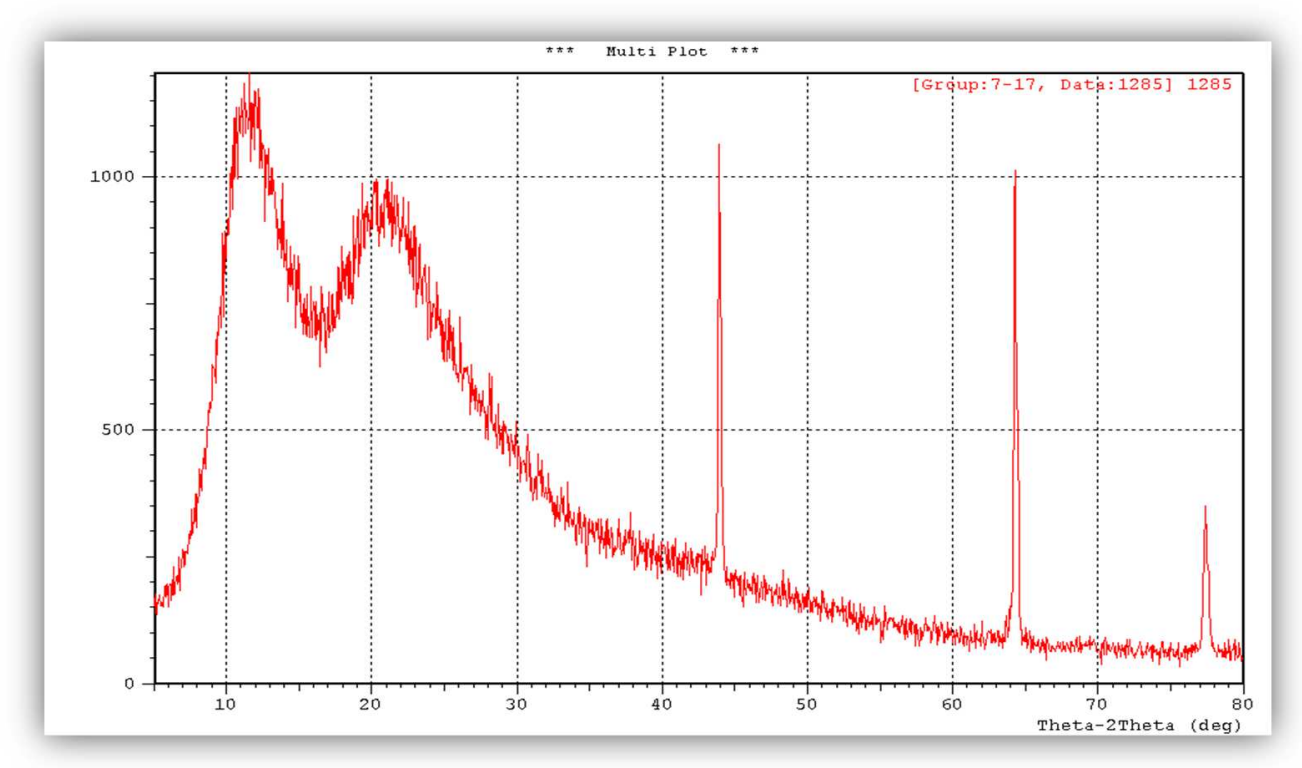

Fig. 17: Powder x-ray diffraction analysis of the PVP K-90

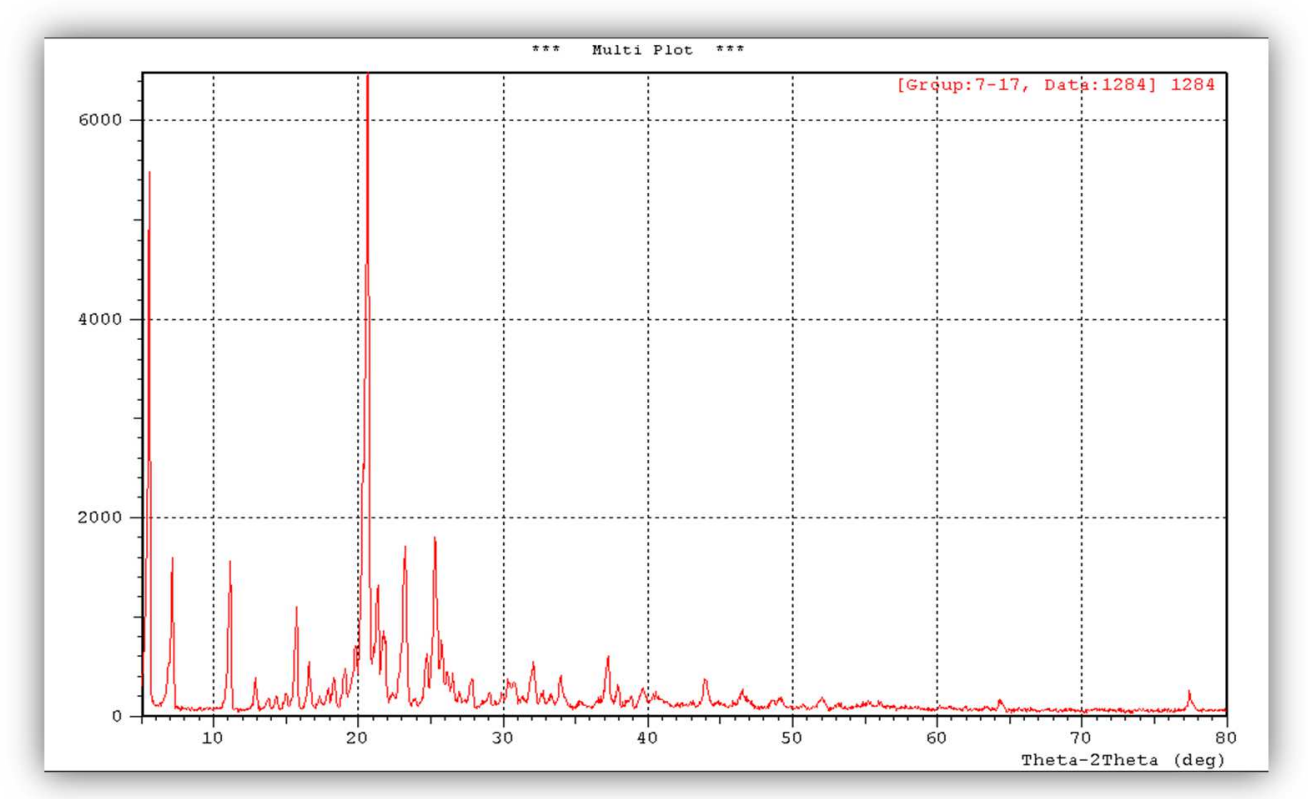

Fig. 18: Powder X-ray diffraction analysis of the selected formula F7

\section{CONCLUSION}

It may be concluded from the results of this study that nanosuspensions of particle water-insoluble drug lafutidine can be prepared using solvent anti-solvent precipitation method and using PVP K90, tween 80, and tween 20 as stabilizers.
The process parameters, such as stabilizer type, the combination of the surfactant with the polymer, stabilizer concentration, stirring speed and combination of other stabilizer were investigated and optimized to produce the smallest drug nanoparticles. The dissolution rate of the nanosuspension significantly enhances as compare with the pure drug. 


\section{ACKNOWLEDGEMENT}

We are very thankful to College of Pharmacy, University of Basrah, Iraq; for providing necessary facilities utilized in carrying out parts of the work.

\section{AUTHORS CONTRIBUTIONS}

All the author have contributed equally

\section{CONFLICT OF INTERESTS}

Declared none

\section{REFERENCES}

1. Marano S, Barker SA, Raimi-Abraham BT, Missaghi S, RajabiSiahboomi A, Craig DQ. Development of micro-fibrous solid dispersions of poorly water-soluble drugs in sucrose using temperature-controlled centrifugal spinning. Eur J Pharm Biopharm 2016;103:84-94.

2. Martin's physical pharmacy and pharmaceutical sciences. 4th Edition; 2006. p. 220.

3. Loh ZH, Samanta AK, Heng PW. Overview of milling techniques for improving the solubility of poorly water-soluble drugs. Asian J Pharm Sci 2015;10:255-74.

4. K Ramesh B, Chandra S, Podile K. Formulation and evaluation of poorly soluble etravirine by spray drying method. Int J Pharm Pharm Sci 2015; 7:98-103.

5. Bhairav BA, Bachhav JK, Saudagar RB. Review on solubility enhancement techniques. Asian J Pharm Res 2016;6:175-80.

6. Khadka P, Ro J, Kim H, Kim I, Kim JT, Kim $\mathrm{H}$, et al. Pharmaceutical particle technologies: an approach to improve drug solubility, dissolution, and bioavailability. Asian J Pharm Sci 2014;9:304-16.

7. Kayaert P, Van den Mooter G. Is the amorphous fraction of a dried nanosuspension caused by milling or by drying? a case study with naproxen and cinnarizine. Eur J Pharm Biopharm 2012;81:650-6.

8. Amin MA, Osman SK, ALY UF. Preparation and characterization of ketoprofen nanosuspension for solubility and dissolution velocity enhancement. Int J Pharm Bio Sci 2013;4:768-80.

9. Sutradhar KB, Khatun S, Luna IP. Increasing possibilities of nanosuspension. J Nanotech 2013. http://dx.doi.org/10.1155/2013/346581

10. Agrawal G, Atrey R, Mishra P. A stability-indicating high performance liquid chromatographic analytical method for the determination of lafutidine in the tablet. Der Pharm Lett 2015; 7:38-43.

11. Parveen A, Reddy RS. Formulation and in vitro evaluation of gastroretentive bilayer floating tablets of clarithromycin and lafutidine. Int J Pharm Tech 2014;6:6651-70.

12. Lolitas D. Design and evaluation of lafutidine floating tablets for controlled release by using semi-synthetic and natural polymer. J Drug Discovery Ther 2014;24:2.

13. Sravanthi N, Bandari D. Effect of super disintegrants on solubility and dissolution rate of lafutidine. Int J Adv Tech Eng Sci 2015;3:275-89.

14. Patel MD, Patel GD, Patel NC. Formulation and optimization of the raft-forming chewable tablet containing lafutidine. Int J Pharm Sci Drug Res 2015;7:229-34.

15. Patel DM, Patel DG, Patel CN. Formulation and optimization of a raft-forming chewable tablet containing lafutidine. Int J Pharm Sci Drug Res 2015;7:229-34.

16. Pandya VM, Patel JK, Patel DJ. Formulation, optimization and characterization of simvastatin nanosuspension prepared by nanoprecipitation technique. Pharm Lett 2011;3:129-40.

17. Jassim ZE, Hussein AA. Formulation and evaluation of clopidogrel tablet incorporating drug nanoparticles. Int J Pharm Pharm Sci 2014;6:838-51.

18. Shid RL, Dhole SN, Kulkarni N, Shid SL. Formulation and evaluation of nanosuspension formulation for drug delivery of simvastatin. Int J Pharm Sci Nanotech 2014;7:2650-65.
19. Sahu BP, Das MK. Nanosuspension for enhancement of oral bioavailability of felodipine. Appl Nanosci 2014;4:189-97.

20. Papdiwal A, Pande V, Aher S. Investigation of an effect of different stabilizers on a formulation of zaltoprofen nanosuspension. Int J Pharm Sci Rev Res 2014;27:244-9.

21. Deore S, Nerkar P, Mahajan H, Ige P. Formulation and evaluation of nanosuspension formulations polymers. Int J Pharm Sci Nanotechnol 2014;8:5-14

22. Gadad AP, Naik SS, Dandagi PM, Bokmal UB. Formulation and evaluation of gastroretentive floating microspheres of lafutidine. Indian J Pharm Educ Res 2016;50Suppl:76-81.

23. Kakran M, Sahoo GN, Li L. Fabrication of nanoparticles of silymarin, hesperetin and glibenclamide by evaporative precipitation of nanosuspension for fast dissolution. Pharm Anal Acta 2015;6:2

24. Jassem NA, Rajab NA. Formulation and in vitro evaluation of azilsartan medoxomil nanosuspension. Int J Pharm Pharm Sci 2017;9:110-9.

25. Wu L, Zhang J, Watanabe W. Physical and chemical stability of drug nanoparticles. Adv Drug Delivery Rev 2011;63:456-69.

26. Sinha B, Müller RH, Möschwitzer JP. Bottom-up approaches for preparing drug nanocrystals: formulations and factors affecting particle size. Int J Pharm 2013;453:1-15.

27. Amin MA, Osman SK, AlyUF. Preparation and characterization of ketoprofen nanosuspension for solubility and dissolution velocity enhancement. Int J Pharm Bio Sci 2013;4:768-80.

28. Krishna K, Hiral K, Navin S, Mahesh D. The impact of critical variables on properties of nanosuspension: a review. Int J Drug Dev Res 2015;7:150-61.

29. Rachmawati H, Shaal LA, Müller RH, Keck CM. Development of curcumin nanocrystal: physical aspects. J Pharm Sci 2013;102:204-14.

30. Zu Y, Sun W, Zhao X, Wang W, Li Y, Ge Y, et al. Preparation and characterization of amorphous amphotericin $B$ nanoparticles for oral administration through liquid anti-solvent precipitation. Eur J Pharm Sci 2014;53:109-17.

31. Senthil Kumar P, Arivuchelvan A, Jagadeeswaran A, Subramanian N, Senthil Kumar C, Mekala P. Formulation, optimization and evaluation of enrofloxacin solid lipid nanoparticles for sustained oral delivery. Asian J Pharm Clin Res 2015;8:231-6.

32. Yeole BD, Patil RP, Lone KD, Tekade AR. Preparation of nanoparticles of poorly water-soluble dronedarone by antisolvent addition technique using the natural polymer as a stabilizer. J Pharm Res Clin Prac 2016;6:8-16.

33. Gera S, Talluri S, Rangaraj N, Sampathi S. Formulation and evaluation of naringenin nanosuspensions for enhancement. AAPS PharmSciTech 2017;18:3151-62.

34. Maaz A, Abdelwahed W, Tekko IA, Trefi S. Influence of nanoprecipitation method parameters on nanoparticles loaded with gatifloxacin for ocular drug delivery. Int J Acad Sci Res 2014;3:1-2.

35. Jünemann D, Dressman J. Analytical methods for dissolution testing of nanosized drugs. J Pharm Pharmacol 2012;64:931-43.

36. Ahuja BK, Jena SK, Paidi SK, Bagri S, Suresh S. Formulation, optimization and in vitro-in vivo evaluation of febuxostat nanosuspension. Int J Pharm 2015;478:540-52.

37. Junyaprasert VB, Morakul B. Nanocrystals for enhancement of oral bioavailability of poorly water-soluble drugs. Am J Pharmacol Sci 2015;10:13-23.

38. Fu X, Kong W, Zhang Y, Jiang L, Wang J, Lei J. Novel solid-solid phase change materials with biodegradable trihydroxy surfactants for thermal energy storage. RSC Adv 2015;5:68881-9.

39. Mishra B, Sahoo J, Dixit PK. Fabrication of cinnarizine nanosuspensions by ultrasonication technique: a systematic study of formulation parameters on particle size and in vitro dissolution. Biopharm J 2017;1:12-21.

40. Vora C, Patadia R, Mittal K, Mashru R. Preparation and characterization of dipyridamole solid dispersions for stabilization of supersaturation: effect of precipitation inhibitors type and molecular weight. Pharm Dev Tech 2016;21:847-55. 